Journal of Thermal Engineering, Vol. 5, No. 5, pp. 414-421, October, 2019

Yildiz Technical University Press, Istanbul, Turkey

\title{
ASSESSING THE IMPACT OF PASSIVE COOLING ON THERMAL COMFORT IN LIG HOUSE USING CFD
}

\author{
N Netam ${ }^{1}$, S Sanyal ${ }^{2}$ and S Bhowmick ${ }^{3, *}$
}

\begin{abstract}
It has been observed that existing low income group (LIG) houses are inefficient to provide thermal comfort in Raipur, Chhattisgarh. This makes more dependency on cooling equipment to achieve thermal comfort which leads to more energy consumption. The objective of the present work is to investigate and enhance the thermal comfort of LIG house by passive cooling techniques. Different cases considered in the present study are, the effect of windows, green roof and green walls and shaded wall etc. on the indoor temperature of LIG house on May 20, 2016. Results concluded that at summer during the early morning, when the outside temperature is lower than the inside temperature, it reduces the room temperature but insufficient to provide thermal comfort. It is also concluded that providing green roof along with green walls enhance the indoor temperature of the house.
\end{abstract}

\section{Keywords: Thermal Comfort, Passive Cooling, Green Roof and Walls}

\section{INTRODUCTION}

On account of modernized ambience, readily available comfort enhancing devices and lack of space, most housing layouts and constructions neglect the possibility of providing comfortable environment naturally. Dependency on external cooling sources has been increasing day by day resulting in increase in energy consumption. This leads to non-conducive living environment and environmental damage. Natural enhancement of thermal comfort, on the other hand, is environment friendly, cost-effective and easily maintainable. Investigation of the thermal performance of buildings help in ascertaining the thermal comfort or lack of it in modern buildings, and the studies allow for avenues of incorporating thermal comfort in a cost-effective manner.

Raipur $\left(21.25^{\circ} \mathrm{N}, 81.63^{\circ} \mathrm{E}\right)$ city is the capital of Chhattisgarh, India, as it experienced the maximum temperature of about $46{ }^{\circ} \mathrm{C}$ at peak summer, a thermal performance analysis of houses for this region can help in assessing the level of thermal comfort. Based on ASHRAE, the National Building Code of India advocates the use of two indoor temperature ranges for thermal comfort; $23{ }^{\circ} \mathrm{C}$ to $26{ }^{\circ} \mathrm{C}$ for summer and $21{ }^{\circ} \mathrm{C}$ to $23{ }^{\circ} \mathrm{C}$ for winter. It has been observed that existing LIG houses hardly provide thermal comfort in Raipur region of Chhattisgarh. The objective of the present work is to investigate and enhance the thermal comfort of LIG house by passive cooling techniques. Any treatment on the building which will reduce the indoor temperature of the building by reducing heat gain to the building is known as passive cooling techniques. Passive cooling systems used in buildings are naturally ventilated buildings, nocturnal ventilative cooling, direct evaporative cooling, indirect evaporative cooling, cooling the soil and green roof/wall. Day time ventilation is used to reduce the indoor temperature; this technique is known as naturally ventilated buildings. Use of ventilation at night time to reduce the indoor temperature is known as nocturnal ventilative cooling. Direct evaporative cooling techniques and indirect evaporative cooling, reduces the indoor temperature by water evaporation direct (desert cooler) and indirect (pond water) method, respectively. Cooling the soil technique uses cool soil as a heat sink to reduce the indoor temperature, and green roof/wall uses vegetation on walls/roof to reduce the indoor temperature. The green roof consists of water proofing layer, drainage, soil and vegetation.

Mathematical model for thermal performance analysis of building by using MATLAB /SIMULINK was developed [1]. Result also shows that high thermal mass building reduces room air temperature of the building. [2] Reported that ventilation improves the physiological comfort of the occupant by creating airflow it is also concluded that if the ambient temperature is higher than the indoor temperature it will increase the room temperature of the building. [3] Presented results from field surveys and simulates the effects of window opening behaviour of office buildings on thermal comfort and energy. When the ambient temperature is lower than indoor temperature, opening a

This paper was recommended for publication in revised form by Regional Editor Sandip Kale

${ }_{1,2,3}$ National Institute of Technology Raipur, 492010, Chhattisgarh, India

${ }^{\star}$ E-mail address: sbhowmick.mech@nitr.ac.in

Orcid id: 0000-0001-8536-5524, 0000-0001-5435-630X, 0000-0001-9799-8724

Manuscript Received 12 January 2018, Accepted 24 March 2018 
window reduces the indoor temperature of the building. Ventilation during the evening is important in hot, humid climates to reduce the discomfort level, because it increases the air speed and enhances sweat evaporation [4]. Simulated the cool roof in Design builder tool, to improve indoor thermal conditions [5]. Results in the study show that a vault roof with high reflectivity coating reduces $53 \%$ in discomfort hours during the summer season as compared to flat roof building. Different passive cooling techniques inside test structures were investigated [6] and concluded that pieces of white glazed tiles fixed over the roof is the best method of cooling of buildings for better thermal comfort conditioning in arid regions. Effect of the window opening in LIG house, at peak hour in summer has been reported. It is concluded that opening of windows at summer increased the indoor temperature.

ANSYS fluent are used in the present study to assess the indoor air temperature of the house. Incorporating green wall, green roof and shading devices are some of the passive cooling techniques to reduce the heat input and enhance temperature of the building are discussed in present work. Different cases are considered in the present study are, the effect of windows opening and size, green roof and green walls and shaded wall (External projection on the wall) on the indoor temperature of LIG house for May 20, 2016. This information will be helpful for the designer to design a house which will provide thermal comfort with less dependency on cooling devices.

\section{BASIC ASSUMPTIONS, INITIAL AND BOUNDARY CONDITIONS}

To determine indoor temperature distribution in LIG house different parameters with different boundary conditions and setting were studied. LIG house was simulated with closed windows, opened windows, green roof and green walls and shaded wall. Intermediate temperature between vegetation soil and concrete roof has been calculated using the conduction heat transfer. It is found that green roof reduces the temperature by $5.43{ }^{\circ} \mathrm{C}$ therefore; simulation has been carried out with the concrete roof and reduced temperature. The similar method has opted for green walls.

The following assumptions were considered for model simulation:

1. The fluid, air is considered as an ideal gas.

2. The flow is laminar.

3. Thermal conductivity, specific heat and density do not vary with time and direction.

4. Convective heat transfer coefficients are constant.

The governing Navier-Stokes equations and radiation model were solved in the three dimensional, parallel, finite-volume solver ANSYS FLUENT v17.1. The cases were solved as stationary, on May 20, 2016. A widely used, the standard k- $\varepsilon$ model was used for closing the set of governing equations. Convective heat transfer coefficient for outer wall and the inner wall is taken as $22.7 \mathrm{~W} / \mathrm{m}^{2} . \mathrm{K}$ and $8.3 \mathrm{~W} / \mathrm{m}^{2} . \mathrm{K}[8]$.

Total solar radiation incident on horizontal and vertical surfaces, which is calculated as follows [9]:

$$
I=I_{d} * \cos (\theta)+I_{d i f f} * \frac{(1+\cos \beta)}{2}+\rho^{*}\left(I_{d}+I_{d i f f}\right) * \frac{(1-\cos \beta)}{2}
$$

In Eq. $15, I_{d}$ is direct radiation, $I_{\text {diff }}$ is diffused solar radiation, $\beta$ is wall inclination angle from horizontal, $\rho$ is ground reflectance (usually 0.2 for normal condition) and $\theta$ is the solar incident angle.

$$
\theta=\cos ^{-1}\left(\begin{array}{l}
\sin \delta \sin \varphi \cos \beta-\sin \delta \cos \varphi \sin \beta \cos \gamma+\cos \delta \cos \varphi \cos \beta \cos \omega \\
+\cos \delta \sin \varphi \sin \beta \cos \gamma \cos \omega+\cos \delta \sin \beta \sin \gamma \sin \omega
\end{array}\right)
$$

In Eq. 2, Declination $(\delta)$ is calculated as follows [9]:

$$
\delta=23.45 \sin \left(360 \frac{284+n}{365}\right)
$$


Journal of Thermal Engineering, Technical Note, Vol. 5, No. 5, pp. 414-421, October, 2019

Here, $n$ is the day of year, $\varphi$ is the latitude, $\gamma$ is Surface azimuth angle $\left(-180^{\circ} \leq \gamma \leq 180^{\circ}\right)$ and $\omega$ is hour angle. Solar radiations on walls have been calculated from the Eq. (1), and are shown in table 1.

Table 1. Boundary conditions

\begin{tabular}{|l|l|l|}
\hline \multicolumn{1}{|c|}{ Parameter } & \multicolumn{2}{c|}{ Values } \\
\hline & \multicolumn{1}{c|}{ At 09:00 hours } & At 12:00 hours \\
\hline Solar radiation at East wall & $643.80 \mathrm{~W} / \mathrm{m}^{2}$ & $279.26 \mathrm{~W} / \mathrm{m}^{2}$ \\
\hline Solar radiation at West wall & $37.6 \mathrm{~W} / \mathrm{m}^{2}$ & $301.08 \mathrm{~W} / \mathrm{m}^{2}$ \\
\hline Solar radiation at roof & $667.14 \mathrm{~W} / \mathrm{m}^{2}$ & $954.98 \mathrm{~W} / \mathrm{m}^{2}$ \\
\hline Ambient temperature & $38.2{ }^{\circ} \mathrm{C}$ & $42{ }^{\circ} \mathrm{C}$ \\
\hline Air velocity & $0.2 \mathrm{~m} / \mathrm{s}$ & $0.4 \mathrm{~m} / \mathrm{s}$ \\
\hline $\begin{array}{l}\text { Convective heat transfer } \\
\text { coefficient at outer wall }\end{array}$ & $22.7 \mathrm{~W} / \mathrm{m}^{2} \mathrm{~K}$ & $22.7 \mathrm{~W} / \mathrm{m}^{2} \mathrm{~K}$ \\
\hline
\end{tabular}

In simulation, the boundary conditions applied to different walls are in terms of sol-air temperature which is calculated as follows:

Sol air temperature:

$$
T_{\text {sol }}=\left(\frac{\alpha I}{h_{o}}+T_{a m b}-\frac{\varepsilon \Delta R}{h_{o}}\right)
$$

In Eq. (4), for horizontal and vertical surface, $\varepsilon \Delta \mathrm{R}=60 \mathrm{~W} / \mathrm{m}^{2}$, and 0 respectively.

For inclined surface; $\varepsilon \Delta \mathrm{R}=(\cot (\beta) \times 60) \mathrm{W} / \mathrm{m}^{2}$.

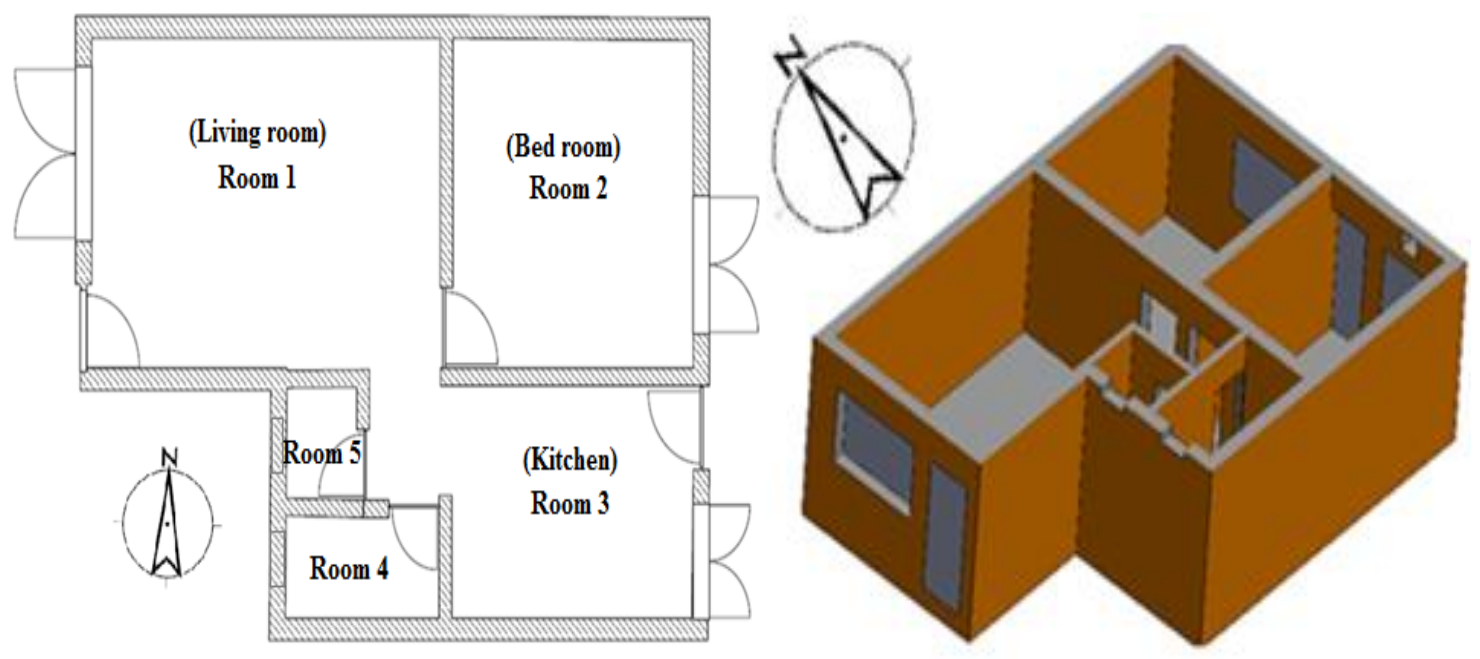

(a)

(b)

Figure 1. (a) LIG house plan (b) 3D view of LIG house 
Table 2. Material properties [10], [11]

\begin{tabular}{|l|l|c|c|}
\hline \multicolumn{1}{|c|}{ Component's name } & Property & Property value & Thickness $(\mathrm{m})$ \\
\hline Green roof with sedum plant & $\mathrm{k}(\mathrm{W} / \mathrm{m}-\mathrm{K})$ & 0.47 & 0.23 \\
\hline Drainage & $\mathrm{k}(\mathrm{W} / \mathrm{m}-\mathrm{K})$ & 0.15 & 0.108 \\
\hline Water proofing & $\mathrm{k}(\mathrm{W} / \mathrm{m}-\mathrm{K})$ & 0.17 & 0.01 \\
\hline Wall & $\mathrm{U}\left(\mathrm{W} / \mathrm{m}^{2} \mathrm{~K}\right)$ & 2.22 & 0.230 \\
\hline Roof & $\mathrm{U}\left(\mathrm{W} / \mathrm{m}^{2} \mathrm{~K}\right)$ & 3.59 & 0.220 \\
\hline Door & $\mathrm{U}\left(\mathrm{W} / \mathrm{m}^{2} \mathrm{~K}\right)$ & 2.2 & 0.025 \\
\hline Glass & $\mathrm{U}\left(\mathrm{W} / \mathrm{m}^{2} \mathrm{~K}\right)$ & 5.1 & 0.0035 \\
\hline
\end{tabular}

\section{METHODOLOGY}

Based on the building plan, the 3D model has been created in SOLIDWORKS (Figure 1); the model is imported in ANSYS fluent for thermal performance analysis. Parametric simulation with the ANSYS fluent was used for analysing the indoor comfort within a LIG house for the climatic condition of Raipur. Indoor temperature of house, with closed windows has been measured using Testo 605i at the height of 3 feet and 7 feet. Results show good agreement with average deviation of $3.7 \%$.

\section{RESULTS}

The simulation results have been validated with the onsite data collected using temperature sensors on $20^{\text {th }}$ May 2016 for house with open window (Room 2) and reported in Table 3.

Table 3. Validation of indoor temperature

\begin{tabular}{|c|c|c|c|}
\hline $\mathbf{1 2 . 0 0}$ hrs. & Onsite data & Simulation Result & \% Error \\
\hline $3 \mathrm{ft}$ & $306.508211\left(33.50^{\circ} \mathrm{C}\right)$ & $307.8\left(34.8^{\circ} \mathrm{C}\right)$ & 3.7 \\
\hline $7 \mathrm{ft}$ & $309.006984\left(36.00^{\circ} \mathrm{C}\right)$ & $310.4\left(37.4^{\circ} \mathrm{C}\right)$ & 3.7 \\
\hline
\end{tabular}

\section{Effect of Windows opening and size on thermal performance}

Simulation results shown in figures 2,3 and 4 reports the temperature distribution at the subsequent height of 3, 5 and 7 feet from the floor respectively on May 20, 2016 (recorded $\mathrm{T}_{\mathrm{amb}}=32^{\circ} \mathrm{C}$ ) at 09:00 hours for the house with different window sizes and closed windows. Figures 2(a), 3(a) and 4(a) show the temperature distribution inside the house for closed windows at the height of 3,5 and 7 feet, respectively.
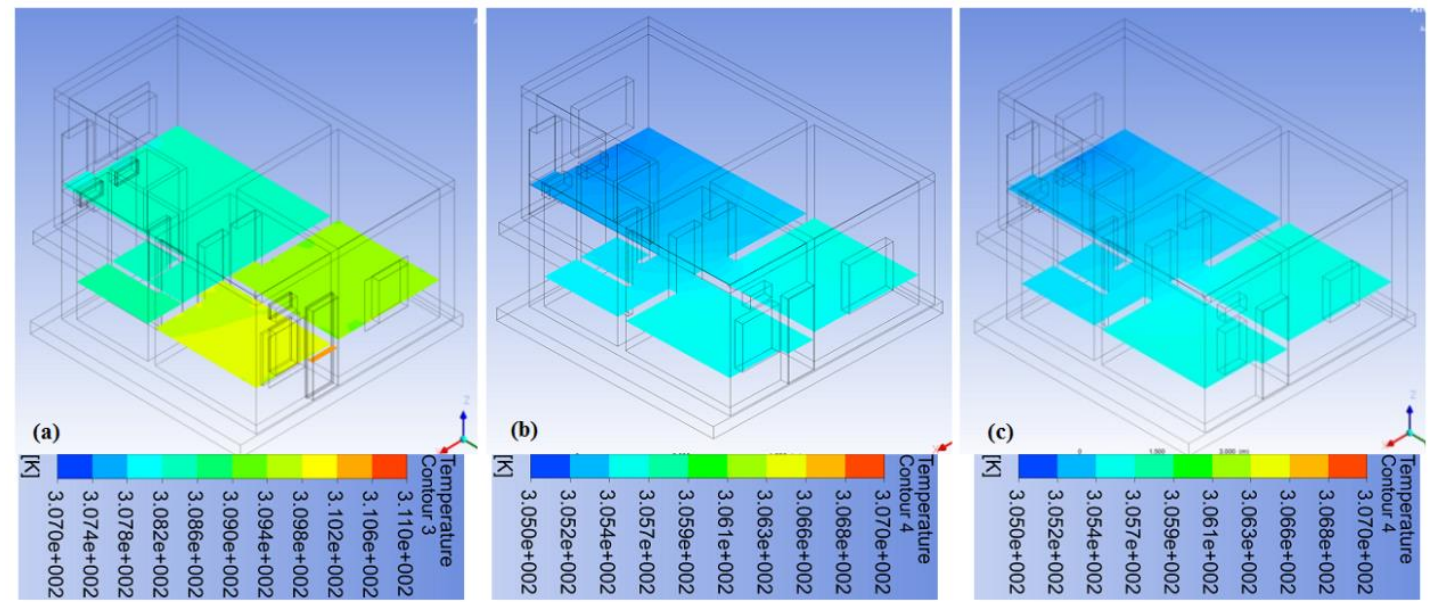

Figure 2. Indoor temperature distribution of the LIG house at 3 feet height on May 20, 2016 at 09:00 hours (a) closed windows (b) opened windows (c) window size reduced to $40 \%$ 

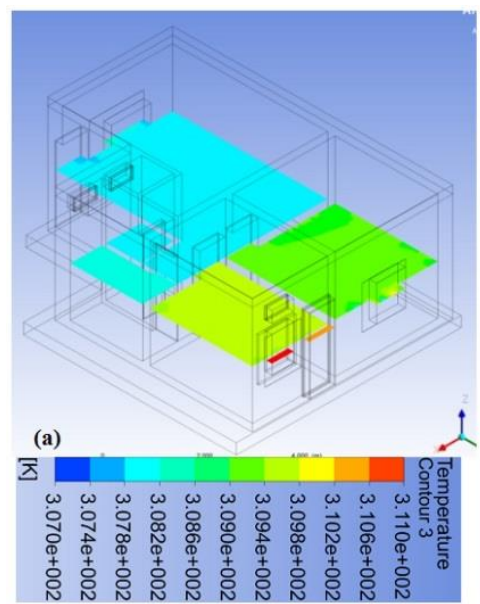
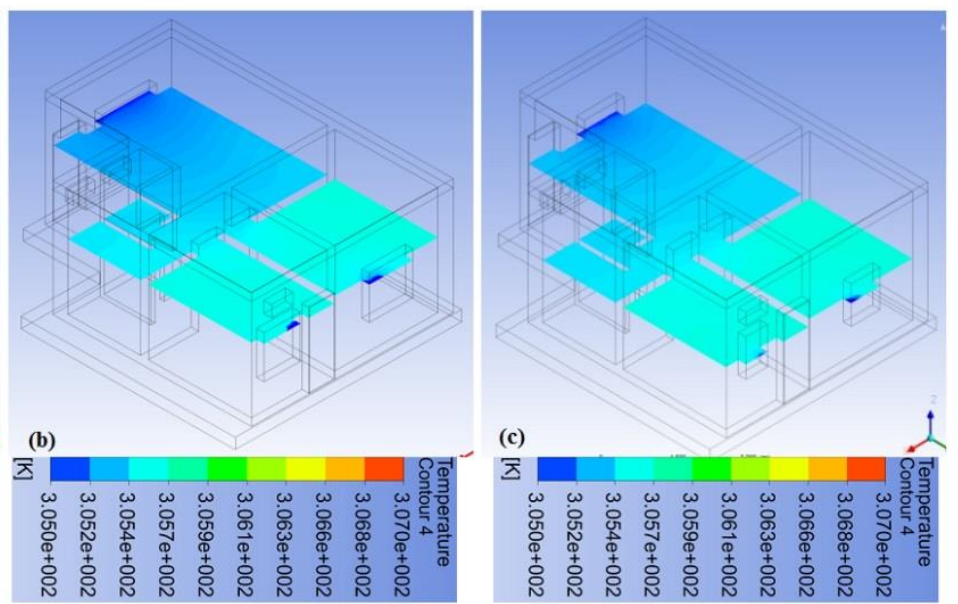

Figure 3. Indoor temperature distribution of the LIG house at 5 feet height on May 20, 2016 at 09:00 hours (a) closed windows (b) opened windows (c) window size reduced to $40 \%$
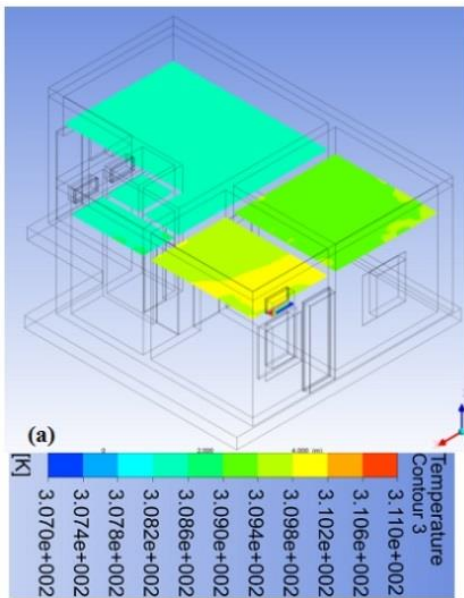
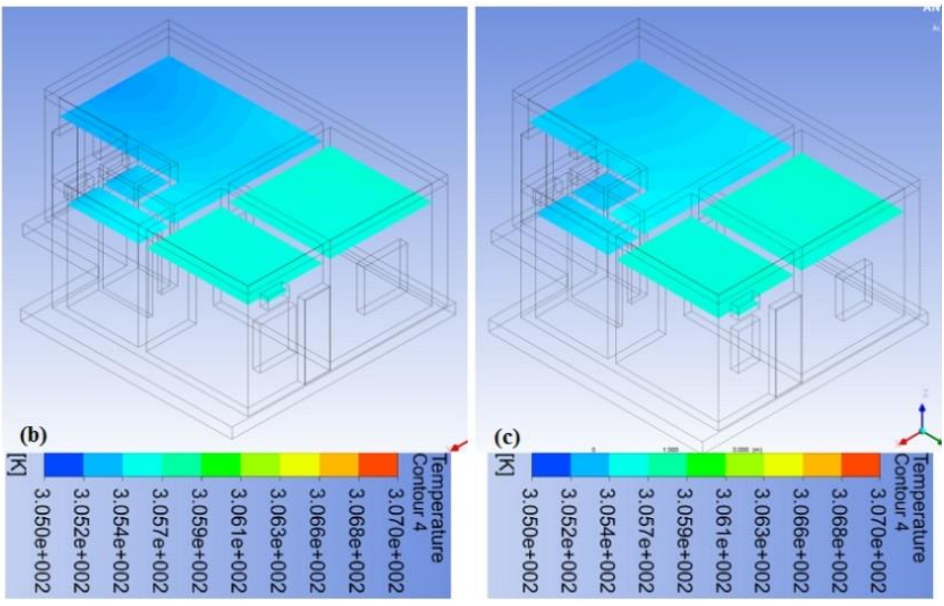

Figure 4. Indoor temperature distribution of the LIG house at 7 feet height on May 20, 2016 at 09:00 hours (a) closed windows (b) opened windows (c) window size reduced to $40 \%$

Figures 2(b), 3(b), 4(b) and 2(c), 3(c), 4(c) show the temperature distribution inside the house, at the different height for opened windows and reduced size (40\%) windows, respectively. The result shows that for summer, window sizes do not matter so much regarding indoor temperature values since all recorded the same temperature values from the simulation. Opened windows at early morning result in lower indoor temperature as compared to closed windows. At early morning and noon, room 2 and room 3 have higher indoor temperature as compared to other at every height.

\section{Effect of Passive Cooling on Thermal Performance}

In the present study, the shared-wall house has been simulated for different roof and wall conditions to reduce the heat gain from the roof and wall to enhance thermal comfort. The LIG houses form a housing colony with each individual house sharing common wall with the adjacent house. These are, hence, termed as shared-wall houses. The results of the simulation are shown in the Figures 5, 6 and 7 which report the indoor temperature distribution for the existing house, shaded wall house, green roof house and green wall with roof house at different height of house at 3 feet, 5 feet and 7 feet on May 20, 2016 at 12:00 hours with ambient temperature of $42^{\circ}$ C. Figures. 5(b), 6(b) and 7(b) show the effect of shaded wall and Figures. 5(c), 6(c) and 7(c) show the effect of the green roof on indoor temperature at the height of 3 feet, 5 feet and 7 feet. Figures 5(d), 6(d) and 7 (d) show that, at peak hours, using green 
walls along with green roof in LIG house gives a superior result as compared to other passive cooling techniques at all the height. Although, shaded wall and green roof individually yield marginal lowering of indoor temperature in comparison to existing house, however, the combined effect of both is substantial as evident from Figures. 5-7(d).
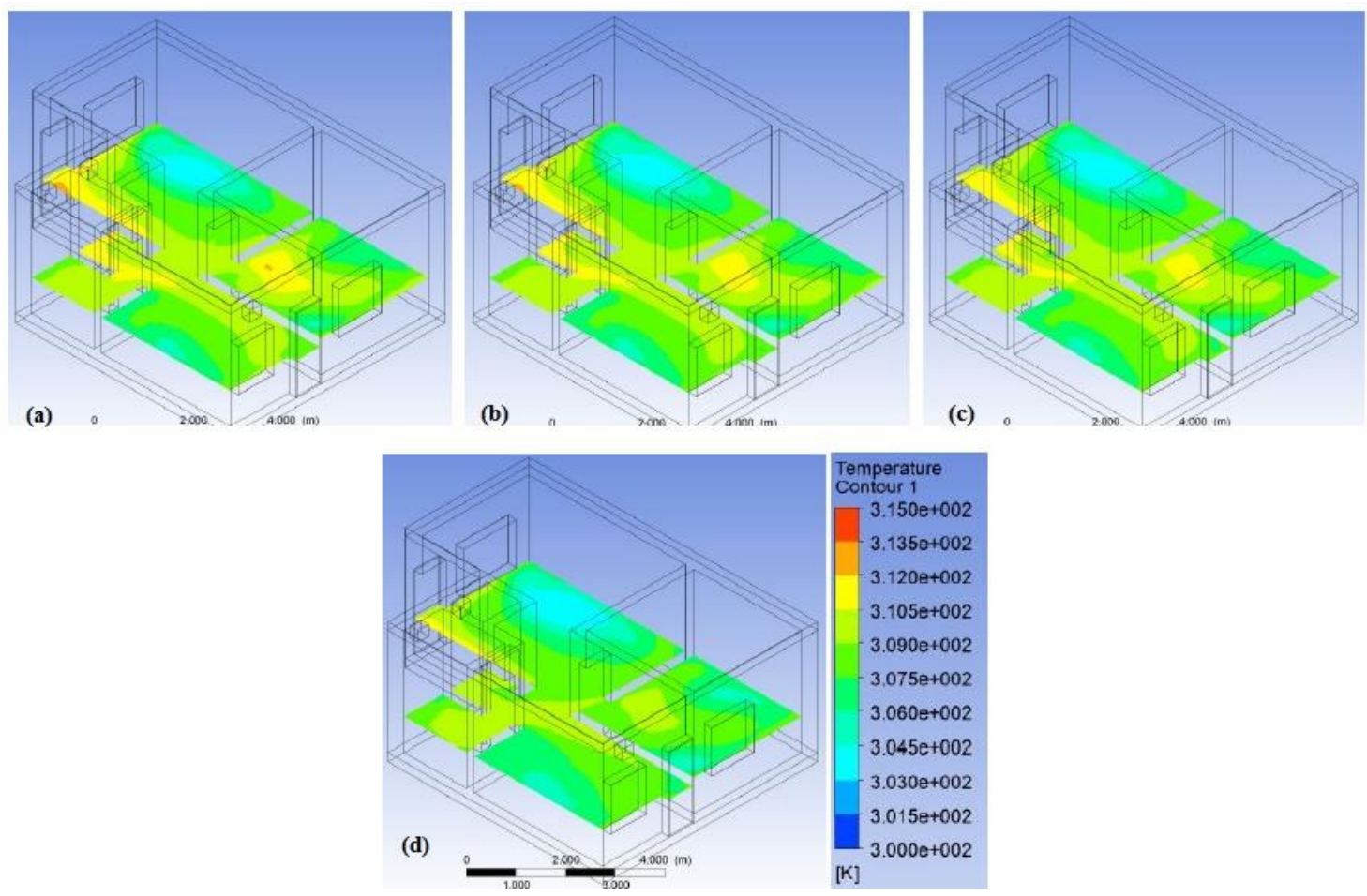

Figure 5. Indoor temperature distribution of the LIG house at 3 feet height on May 20, 2016 at 12:00 hours (a) existing house (b) shaded house (c) green wall (d) green walls and roof
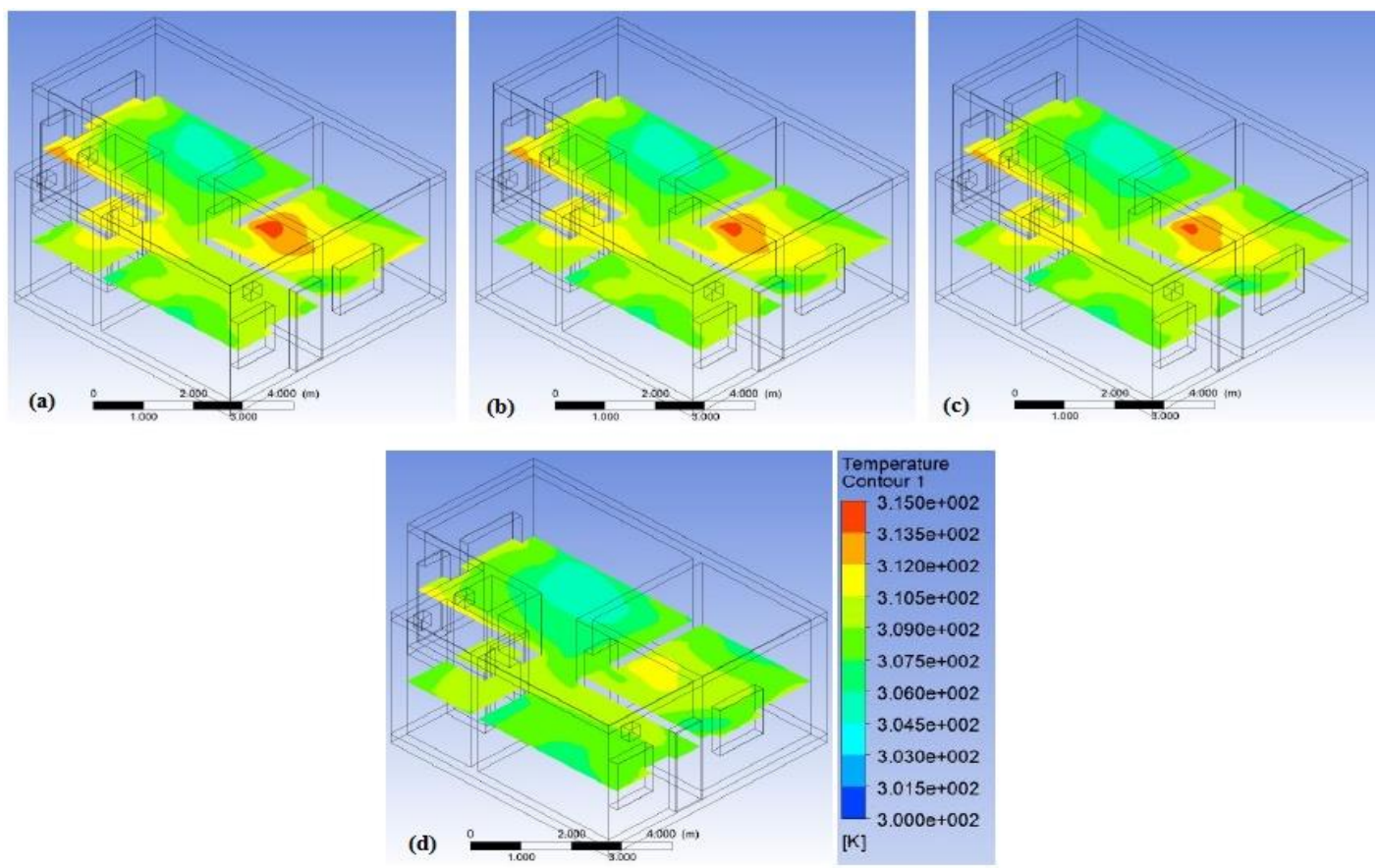

Figure 6. Indoor temperature distribution of the LIG house at 5 feet height on May 20, 2016 at 12:00 hours (a) existing house (b) shaded house (c) green wall (d) green walls and roof 

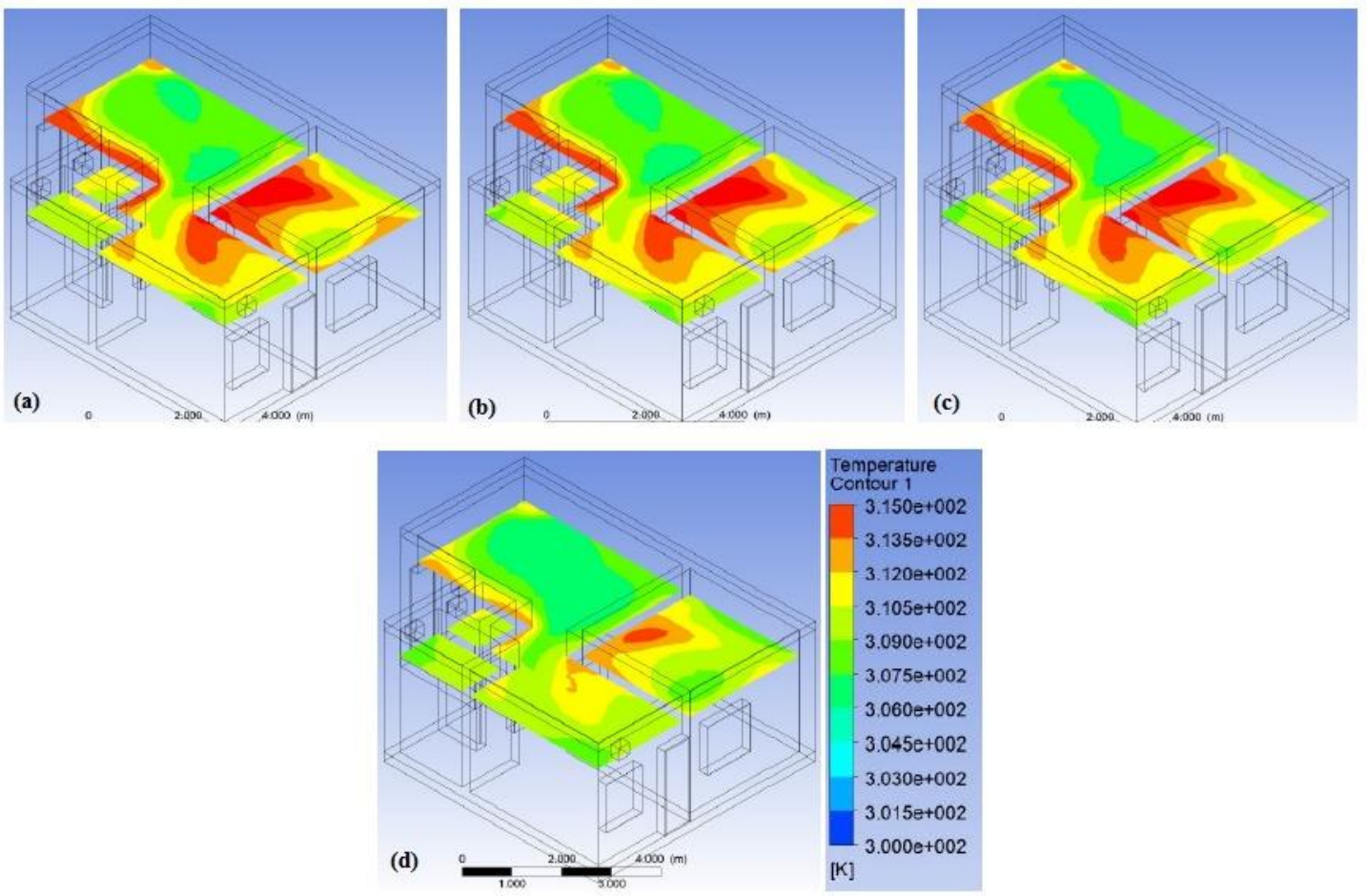

Figure 7. Indoor temperature distribution of the LIG house at 7 feet height on May 20, 2016 at 12:00 hours (a) existing house (b) shaded house (c) green wall (d) green walls and roof.

\section{CONCLUSION}

Through parametric simulation, the effect of window sizes and passive cooling techniques on indoor temperature has been studied. The study shows that the sizes of the window on the building do not affect indoor temperature significantly in summer at early morning. In summer during night time, when the outside temperature is lower than the indoor temperature, it reduces the room temperature but is insufficient to provide thermal comfort. It is also concluded that providing green roof along with green walls enhance the indoor temperature of the house by approximately $4^{\circ} \mathrm{C}$, it gives better results as compared to other passive techniques.

\section{NOMENCLATURE}

$\begin{array}{ll}C & \text { Specific heat }(\mathrm{J} / \mathrm{kg} \cdot \mathrm{K}) \\ \mathrm{h}_{\mathrm{o}} & \text { Convective heat transfer coefficient at outer wall } \\ \mathrm{k} & \text { Thermal conductivity }(\mathrm{W} / \mathrm{m} \cdot \mathrm{K}) \\ \mathrm{T} & \text { Temperature }(\mathrm{K}) \\ \mathrm{T}_{\text {amb }} & \text { Ambient temperature }(\mathrm{K}) \\ \mathrm{U} & \text { Overall heat transfer coefficient }\left(\mathrm{W} / \mathrm{m}^{2} . \mathrm{K}\right) \\ u, v, w & \text { Velocity }(\mathrm{m} / \mathrm{s}) \\ \rho & \text { Density }\left(\mathrm{kg} / \mathrm{m}^{3}\right) \\ \text { amb } & \text { Ambient }\end{array}$

\section{REFERENCES}

[1] Mendes N., Oliveira G. H. C., Araújo H. X. D. (2001). Building thermal performance analysis by using matlab/Simulink, Seventh International IBPSA Conference.

[2] Evola G., \& Popov V. (2006). Computational analysis of wind driven natural ventilation in buildings, Energy and Building, 38(5), 491-501. 
[3] Rijal H. B., Tuohy P., Humphreys M. A., Nicol J. F., Samuel A. and Clarke J. (2007). Using results from field surveys to predict the effect of open windows on thermal comfort and energy use in buildings, Energy and Building., 39(7), 823-836.

[4] Givoni B. (2011). Indoor temperature reduction by passive cooling systems, Solar Energy, 85(8), 16921726.

[5] Dabaieh M., Wanas O., Amer M. and Johansson E. (2015). Reducing cooling demands in a hot dry climate : A simulation study for non-insulated passive cool roof thermal performance in residential buildings, Energy and Builing, 89, 142-152.

[6] Nahar N. M., Sharma P., \& Purohit M. M. (2003). Performance of different passive techniques for cooling of buildings in arid regions, Building and Environment, 38, 109-116.

[7] Netam N., Sanyal S. and Bhowmick S. (2017). Thermal Performance Analysis to Assess Inhabitant Comfort inside LIG houses in Chhattisgarh, International. Journal of Theoretical Applied Mechanics, 12 (3), 613-622.

[8] Nayak J. and Prajapati J. (2006). Thermal Performance of Building, Handbook of Energy Conscious Building 38.

[9] Duffie J., Beckman W. and Worek W. M. (1994). Solar Engineering of Thermal Processes, 2nd edition, John Wiley \& Sons, New York.

[10] Morau D., Libelle T. and Garde F. (2012). Performance evaluation of green roof for thermal protection of buildings in reunion island, Energy and Building 14(262), 1008-1016.

[11] Lazzarin R. M., Castellotti F. and Busato F. (2005). Experimental measurements and numerical modelling of a green roof, Energy and Building, 37, 1260-1267. 